\title{
Fungal plant cell wall-degrading enzyme database: a platform for comparative and evolutionary genomics in fungi and Oomycetes
}

\author{
Jaeyoung Choi ${ }^{1,2}$, Ki-Tae Kim ${ }^{1,2}$, Jongbum Jeon ${ }^{1,2}$, Yong-Hwan Lee ${ }^{1,2,3,4,5,6^{*}}$ \\ From Asia Pacific Bioinformatics Network (APBioNet) Twelfth International Conference on Bioinformatics \\ (InCoB2013) \\ Taicang, China. 20-22 September 2013
}

\begin{abstract}
Background: Plant cell wall-degrading enzymes (PCWDEs) play significant roles throughout the fungal life including acquisition of nutrients and decomposition of plant cell walls. In addition, many of PCWDEs are also utilized by biofuel and pulp industries. In order to develop a comparative genomics platform focused in fungal PCWDEs and provide a resource for evolutionary studies, Fungal PCWDE Database (FPDB) is constructed (http://pcwde.riceblast.snu.ac.kr/).

Results: In order to archive fungal PCWDEs, 22 sequence profiles were constructed and searched on 328 genomes of fungi, Oomycetes, plants and animals. A total of 6,682 putative genes encoding PCWDEs were predicted, showing differential distribution by their life styles, host ranges and taxonomy. Genes known to be involved in fungal pathogenicity, including polygalacturonase (PG) and pectin lyase, were enriched in plant pathogens. Furthermore, crop pathogens had more PCWDEs than those of rot fungi, implying that the PCWDEs analysed in this study are more needed for invading plant hosts than wood-decaying processes. Evolutionary analysis of PGs in 34 selected genomes revealed that gene duplication and loss events were mainly driven by taxonomic divergence and partly contributed by those events in species-level, especially in plant pathogens.

Conclusions: The FPDB would provide a fungi-specialized genomics platform, a resource for evolutionary studies of PCWDE gene families and extended analysis option by implementing Favorite, which is a data exchange and analysis hub built in Comparative Fungal Genomics Platform (CFGP 2.0; http://cfgp.snu.ac.kr/).
\end{abstract}

\section{Background}

Plant cell wall-degrading enzymes (PCWDEs) play significant roles throughout the fungal life including acquisition of nutrients and decomposition of plant cell walls. Particularly for plant pathogens, it is critical to decide where and when to start intruding into the host cell. Many plant pathogens are known to secrete a variety of PCWDEs to perceive weak regions of plant epidermal cells and penetrate the plant primary cell wall. For example, a cutinase (CUT2) in the rice blast fungus, Magnaporhte oryzae, is known to play roles in hydrophobic surface sensing,

\footnotetext{
* Correspondence: yonglee@snu.ac.kr

'Fungal Bioinformatics Laboratory, Seoul National University, Seoul 151-921, Korea

Full list of author information is available at the end of the article
}

differentiation and virulence on rice and barley [1]. As another example of cutinase, disruption of CutA from Fusarium solani f. sp. pisi is responsible for decreased virulence on pea [2]. Additionally, degradation of xylan and pectin is required for fungal pathogens to invasively penetrate and proliferate inside host cells. In M. oryzae, some endoxylanases are thought to be responsible for fungal pathogenicity, even if three of them, XYL1, XYL2 and XYL6, are not required for pathogenicity [3]. According to the analysis between life styles and eight substrates including xylan and xyloglucan, pathogenic fungi showed more hydrolytic activities [4] implying the importance of these enzymes. Among the pectinolytic enzymes, many characterized polygalacturonases (PGs), Bcpg1, Cppg1-2 and P2c from Botrytis cinerea, Claviceps purpurea and Aspergillus
C Biomed Central

(c) 2013 Choi et al.; licensee BioMed Central Ltd. This is an open access article distributed under the terms of the Creative Commons Attribution License (http://creativecommons.org/licenses/by/2.0), which permits unrestricted use, distribution, and reproduction in any medium, provided the original work is properly cited. 
flavus, respectively, are known to be responsible for successful infection on their hosts [5-7]. Besides the phytopathological impact mentioned above, PCWDEs have attained a lot of attention for their potential applications in pulp and biofuel industries, to find and develop the most economic and efficient combinations of enzymes to yield fermentable saccharides from plant biomass [4].

Even though a large number of genomes are available, there is no systematic platform for dissecting the genes encoding PCWDEs especially in the fungal kingdom. Although Carbohydrate-Active Enzymes (CAZY) database archives a wide spectrum of glycosyl hydrolases [8], it is not focused on fungi and not all of them are PCWDEs. In order to understand fungal PCWDEs in kingdom level, we developed a new web-based platform, Fungal PCWDE Database (FPDB; http://pcwde.riceblast.snu.ac.kr/), to identify and classify genes encoding PCWDEs from fungal genomes (Figure 1).

We selected four major components of plant cell wall that are well-studied and/or critical for pathogen-host interactions. Subsequently, 22 gene families, including five subfamilies, are selected by materials they degrade (Table 1). First of all, cuticle layer is the outermost barrier of plant epidermal tissue and important for that it is the first defence line against pathogens. Another component is pectin which constructs major skeleton of plant cell walls and is hard to degrade. The others are cellulose and hemicellulose, the most plentiful components of the primary cell wall, including xylan, xyloglucan and galactoglucomannan $[9,10]$. The 22 gene families have been divided into two categories, main-chain degrading and accessary PCWDEs. The main-chain degrading PCWDEs participate in breakdown of highly polymeric backbone compounds, such as cutin polymer, (gluco)xylan, pectin or glucan. On the other hand, accessary PCWDEs degrade derivatives that the main-chain degrading PCWDEs produce, for example, xylobiose or many forms of oligo-/di-saccharides into respective monomers, hence producing ready-to-use carbon sources (Table 1).

In this study, we summarize the inventory of fungal genes encoding PCWDEs over the taxonomy. In addition, we also conduct comparative genomic analysis to elucidate differences among various fungal life styles and host ranges regarding the roles of PCWDEs in fungal pathogenesis. Lastly, evolutionary duplications and losses of genes encoding PGs are analyzed to elucidate more about the differential distribution of genes encoding PCWDEs.

\section{Results and discussion}

\section{Identification of genes encoding PCWDEs}

From 328 genomes, 6,682 genes are predicted to encode 22 gene families of PCWDEs (Figure 1). To evaluate the confidence level of the predicted genes, we performed the statistical analysis with positive and negative sets from
UniProtKB/SwissProt [11], a manually curated protein database. The sensitivity and specificity reached to $95.31 \%$ and $98.55 \%$, respectively. These results indicate that our pipeline not only accurately captures fungal signatures of PCWDEs, but also has a good discrimination power against the protein sequences from closely related enzymes to the PCWDEs. When comparing the average number of genes per species, plant genomes present the largest number (39.00 genes per genome), followed by Oomycetes (28.60) and fungi (20.01). Existence of signatures of fungal PCWDEs in other kingdoms suggests that these domains are quite universal and they could have diverse roles along with their niches and life styles.

Understandably, the most commonly found enzymes are related to the process of breaking the bond within dimer or polymer of glucose or mannose, as they are the most simple sugar sources that can be readily utilized by the life organisms [12]. The most common gene found in 304 genomes is alpha-glucosidase (Type 1), which hydrolyzes disaccharides and is usually involved in the endmost step of polysaccharide catabolism. In the second place, alpha-mannosidases (Type 1 and 2), cleaving alpha-form of mannose polymers, are found in at least 238 genomes (Additional file 1). The products of these two genes could be considered as PCWDEs, as they are involved in catabolism and turnover of plant $N$-glycans [13].

According to the identification results, fungi are the only taxon predicted to have genes encoding endoarabinase, alpha-glucuronidase, cutinase, endoxylanase (Type 2) and cellobiohydrolase (Type 2). In addition, three genes encoding pectin-degrading enzymes are found only in fungi and Oomycetes (pectin lyase, pectate lyase and rhamnogalacturonan lyase).

When considered parasitic life style of Plasmodium spp., it should come as no surprise that genes encoding PCWDEs are not predicted in these species, because they utilize molecular machineries from their hosts [14]. On the contrary, species from the Kingdoms Metazoa only have genes that are involved in basic polysaccharide degradation, such as mannosidases and glucosidases. In plants, two pectinolytic enzymes, PG and pectin methylesterase, are highly enriched that are essentially required for cell wall extension and fruit ripening [15]. In fungi and Oomycetes, however, more diverse gene families are found, especially in Pezizomycotina and Oomycetes. Among the species in Pezizomycotina, all of the 22 gene families are predicted, and PGs and pectate lyases are the most frequently found. Many enzymes which could be used as arsenal for invading plant cells are found only in fungi and Oomycetes, such as cutinase, endoxylanase (Type 2), pectate lyase and pectin lyase that imply their roles in pathogenesis (Figure 2). Secretome analysis by using Fungal Secretome Database (FSD; http://fsd.snu.ac.kr/) [16] has shown that $91.28 \%$ of these enzymes, on average, are 




Figure 1 A constructed pipeline for prediction of PCWDEs. In silico prediction pipeline in the FPDB is illustrated as a flowchart. See Materials and Methods section for more details of each process.

predicted to be secretory (Table 2), indicating their importance at the apoplastic interface between fungal and host cell walls. Moreover, particularly in case of M. oryzae, 33 predicted PCWDEs are detected by either of in planta apoplastic secretome analysis or transcriptome profiling experiments $[17,18]$. These 33 PCWDEs also include three cutinases, eight endoxylanases, three pectate lyases and two PGs, suggesting their critical roles for successful infection to the host cells (Additional file 2). 
Table 1 List of gene families archived in the FPDB

\begin{tabular}{|c|c|c|c|c|}
\hline Substrate & Category & Gene Family & Number of Genes & Number of Genomes \\
\hline Cutin & Leaf Surface & Cutinase & 112 & 39 \\
\hline \multirow[t]{4}{*}{ Cellulose } & Main-chain degrading & Cellobiohydrolase (Type 1) & 174 & 59 \\
\hline & Main-chain degrading & Cellobiohydrolase (Type 2) & 71 & 35 \\
\hline & Accessary & Alpha-glucosidase (Type 1) & 1,060 & 304 \\
\hline & Accessary & Alpha-glucosidase (Type 2) & 834 & 197 \\
\hline \multirow[t]{10}{*}{ Pectin } & Main-chain degrading & Alpha-rhamnosidase & 178 & 53 \\
\hline & Main-chain degrading & Pectate lyase & 119 & 39 \\
\hline & Main-chain degrading & Pectin lyase & 130 & 38 \\
\hline & Main-chain degrading & Polygalacturonase & 713 & 163 \\
\hline & Main-chain degrading & Rhamnogalacturonan lyase & 96 & 50 \\
\hline & Accessary & Beta-D-galactosidase (Type 1) & 90 & 59 \\
\hline & Accessary & Beta-D-galactosidase (Type 2) & 262 & 104 \\
\hline & Accessary & Endoarabinase & 43 & 31 \\
\hline & Accessary & Pectin methylesterase & 448 & 77 \\
\hline & Accessary & Rhamnogalacturonan acetylesterase & 57 & 45 \\
\hline \multirow[t]{3}{*}{ Xylan } & Main-chain degrading & Endoxylanase (Type 1) & 171 & 64 \\
\hline & Main-chain degrading & Endoxylanase (Type 2) & 122 & 51 \\
\hline & Accessary & Alpha-glucuronidase & 41 & 35 \\
\hline \multirow[t]{4}{*}{ Galacto(gluco)mannan } & Main-chain degrading & Alpha-mannosidase (Type 1) & 1,310 & 300 \\
\hline & Main-chain degrading & Alpha-mannosidase (Type 2) & 267 & 242 \\
\hline & Main-chain degrading & Beta-endo-mannnanase & 176 & 67 \\
\hline & Main-chain degrading & Beta-mannosidase & 208 & 147 \\
\hline
\end{tabular}

\section{Differential distribution of PCWDEs by life styles}

A total of 215 fungal and Oomycete genomes are divided into five groups of life styles; animal pathogen, opportunistic animal pathogen, plant pathogen, parasite and saprophyte. Tremella mesenterica, a parasite of wood-decaying fungi in the genus Peniophora, is predicted to have accessary enzymes to break down di-/oligo-saccharides. Analogous composition of the genes is found in animal pathogens. They do not have the genes belonging to at least 15 gene families, only presenting genes encoding enzymes for polysaccharide degradation including alphaglucosidase and alpha-/beta-mannosidase (Additional file 3). As their host range is limited to animals, it is natural that they do not encode pectin- or xylan-degrading enzymes.

The distribution of opportunistic animal pathogen could be divided into two subgroups, species in Pezizomycotina and Saccharomycotina. Among the opportunistic animal pathogen, most of PCWDEs are found in the species belonging to Pezizomycotina, while only alpha-/ beta-mannosidase and alpha-glucosidase are found in three Candida spp. (Additional file 3) This result supports that duplication and loss events of genes encoding PCWDEs might be mainly driven by taxonomic divergence. Gene distribution in plant pathogens is quite diverse and much more genes are enriched in species belonging to Pezizomycotina. In the subphylum
Pezizomycotina, pectate/pectin lyase and PG are intensively enriched enzymes that are known to be responsible for pathogenicity of fungal pathogens $[5-7,19,20]$ (Additional file 3).

\section{Differential distribution of PCWDEs among plant- associated fungi}

Wood-decaying fungi attack and digest moist wood, causing diverse rot diseases. Interestingly, rot fungi do not possess as many genes encoding PCWDEs as plant pathogens do. This is mainly because there is no duplication event after divergence of Ascomycota and Basidiomycota, except species-level events (Figure 3). In fact, unlike crop pathogenic fungi, ligninolytic enzymes, such as laccases and peroxidases, are more important in wood-decaying fungi that are essential to cause rot symptoms [21]. Five rot fungi included in this analysis are Phanerochaete chrysosporium, Pleurotus ostreatus PC9, Dichomitus squalens, Heterobasidion irregulare TC 32-1 and Serpula lacrymans which cause either brown rot, red rot, white rot or root rot, respectively. No pectin lyase-encoding gene is predicted from their genomes and only at most three copies of PG-encoding genes are predicted. In contrast, important plant pathogens such as Phytophthora infestans, Colletotrichum higginsianum, Fusarium oxysporum and two Verticillium spp. have at least 5 and 11 genes encoding pectin lyase and PG, respectively (Additional file 3 ). 


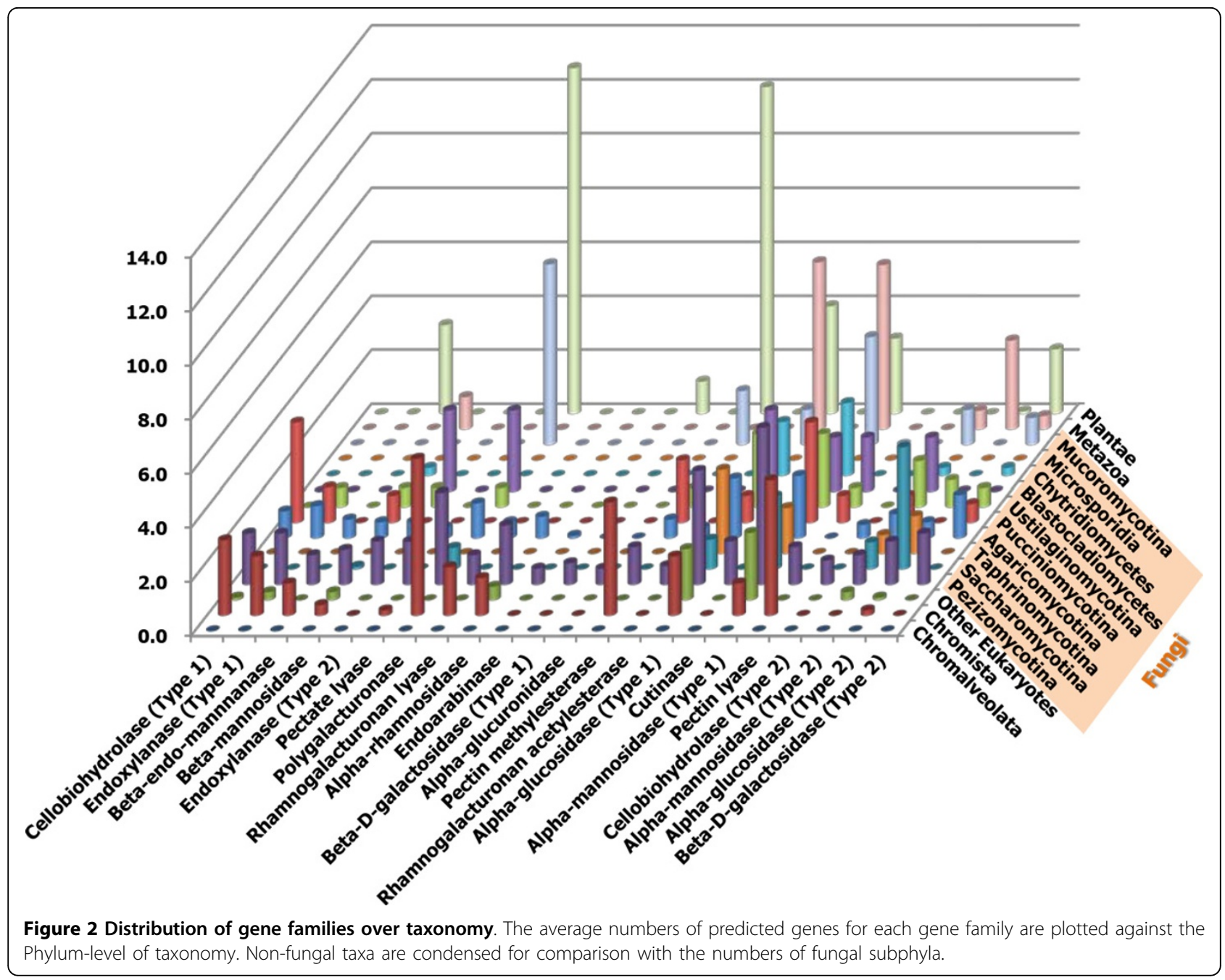

It supports that those highly enriched PCWDEs in plant pathogens are likely to be utilized within pathogenic interactions with a host, rather than decaying dead materials.

\section{Tracking evolutionary history of PGs}

Among the pectin-degrading enzymes, PG is the most frequently found one. However, genes encoding PG are found only in Oomycetes, fungi and plants. This is might be due to the fact that PG is known to be involved in ripening of fruits for plants and rotting process especially by fungi [15]. For fungi, plant pathogens in particular, to successfully colonize on plant surface, they need to pass through the primary cell wall where pectin is highly concentrated [22]. Although some PGs are proven to be irrelevant with pathogenicity [23], majority of them would play roles outside fungal cells when considering that their target substrate is always outside fungal cell. In addition,

Table 2 Secretory potential of PCWDEs in fungi and Oomycetes

\begin{tabular}{cccccc}
\hline & Number of Fungal/Oomycete Genes & ClassSP* & ClassSP $^{3 *}$ & ClassSL* $^{*}$ & Number of Secretory Proteins * \\
\hline Cutinase & 112 & 101 & 1 & 0 & $102(91.07 \%)$ \\
Endoxylanase (Type 1) & 168 & 152 & 3 & 0 & $155(92.26 \%)$ \\
Endoxylanase (Type 2) & 122 & 112 & 1 & 0 & $113(92.62 \%)$ \\
Pectate lyase & 119 & 108 & 2 & 0 & $110(92.44 \%)$ \\
Pectin lyase & 130 & 110 & 5 & 1 & $116(89.23 \%)$ \\
Polygalacturonase & 392 & 343 & 12 & 1 & $356(90.82 \%)$
\end{tabular}

* ClassSP, ClassSP ${ }^{3}$ and ClassSL indicate the classes of secretory proteins defined in the FSD [16]. The number of secretory proteins is the sum of the three classes. Proportion of sequences with secretory potential is shown in parenthesis. 




Figure 3 Reconciled tree of PGs. The reconciled tree for PGs from 34 species in FGGS. Genes encoding PG are only found in 19 species. The other species which do not have genes encoding PGs are not included in this figure. The numbers of duplication (D) and loss (L) events are shown in the corresponding internal nodes. The numbers of events at species-level are presented next to the name of leaf nodes. Species names are abbreviated as the followings: Fo (Fusarium oxysporum), Fg (Fusarium graminearum), Cg (Colletotrichum graminicola M1.001), Mo (Magnaporthe oryzae 70-15), Nc (Neurospora crassa), Bc (Botrytis cinerea), Af (Aspergillus fumigatus Af293), An (Aspergillus nidulans), Um (Ustilago maydis 521), Cn (Cryptococcus neoformans var. grubii H99), PC (Phanerochaete chrysosporium), Hi (Heterobasidion irregular TC 32-1), Sc

(Saccharomyces cerevisiae S288C), Ro (Rhizopus oryzae), Pb (Phycomyces blakesleeanus), Am (Allomyces macrogynus), Pi (Phytophthora infestans), Os (Oryza sativa) and At (Arabidopsis thaliana).

356 out of 392 putative PGs from fungi and Oomycetes are predicted to be secretory [16] (Table 2).

To investigate evolutionary track of a catalytic domain of PGs, genes from 34 species are selected (Table 3). As 15 species do not have the predicted genes, a gene tree and a species tree of the remaining 19 species are subjected to reconciliation analysis. Interestingly, the reconciled tree show intensive gene duplications and losses. In particular, losses only occurred in fungi, not in Phytophthora infestans and plants. All the fungi analysed have gone through at least 14 losses. The highest number of losses that had occurred is 20, where detected in Neurospora crassa and M. oryzae (Figure 3). The common ancestral gene(s) would have existed before the divergence of plants and fungi, and a large loss of PGs occurred at divergence between fungi and Oomycetes. After entering into fungi, another duplication event occurs at the divergence between the phyla Ascomycota and Basidiomycota. This duplication has preserved only in Aspergillus spp. and $B$. cinerea, while the other ascomycetes have undergone at least one loss event (Figure 3). These gain and loss events happened along with taxonomic hierarchy, rather than different fungal life styles. However, there have been duplication and loss events at species-level in 10 species, supporting that adaptation to local environments might partly contribute the evolution of the PGs. In accordance with the whole genome duplication and expansion of gene families in Rhizopus oryzae [24], a dramatic duplication event is detected at the degree of 15 , presenting 18 predicted PGs (Figure 3).

\section{Utility}

\section{Web interfaces}

To provide user-friendly and intuitive user experience, the web pages of the FPDB are concisely designed by adopting Data-driven User Interface of Comparative Fungal Genomics Platform (CFGP 2.0; http://cfgp.snu.ac. $\mathrm{kr} /$ ) [25]. In silico identified genes encoding PCWDEs can be browsed by either species or gene families. In the Species Browser, kingdom-level and phylum-level of statistics are provided as well as download option for distribution of PCWDEs in all the 328 genomes. In the Gene Family Browser, distribution along with subphylum-level taxonomy is available for every gene family, providing a glimpse of distribution across the large number of genomes (Figure 4). 
Table 3 List of genomes for phylogenomic analysis

\begin{tabular}{|c|c|c|c|c|}
\hline Species Name & Kingdom & Phylum & Subphylum & Life Style* \\
\hline Aspergillus fumigatus Af293 & Fungi & Ascomycota & Pezizomycotina & Animal pathogen \\
\hline Aspergillus nidulans & Fungi & Ascomycota & Pezizomycotina & Saprotroph \\
\hline Blumeria graminis & Fungi & Ascomycota & Pezizomycotina & $\begin{array}{l}\text { Plant pathogen } \\
\text { (Biotroph) }\end{array}$ \\
\hline Botrytis cinerea & Fungi & Ascomycota & Pezizomycotina & $\begin{array}{l}\text { Plant pathogen } \\
\text { (Necrotroph) }\end{array}$ \\
\hline Coccidioides immitis RS & Fungi & Ascomycota & Pezizomycotina & Animal pathogen \\
\hline Colletotrichum graminicola M1.001 & Fungi & Ascomycota & Pezizomycotina & $\begin{array}{l}\text { Plant pathogen } \\
\text { (Hemibiotroph) }\end{array}$ \\
\hline Fusarium graminearum & Fungi & Ascomycota & Pezizomycotina & $\begin{array}{l}\text { Plant pathogen } \\
\text { (Necrotroph) }\end{array}$ \\
\hline Fusarium oxysporum & Fungi & Ascomycota & Pezizomycotina & $\begin{array}{l}\text { Plant pathogen } \\
\text { (Necrotroph) }\end{array}$ \\
\hline Histoplasma capsulatum H88 & Fungi & Ascomycota & Pezizomycotina & Animal pathogen \\
\hline Magnaporthe oryzae $70-15$ & Fungi & Ascomycota & Pezizomycotina & $\begin{array}{l}\text { Plant pathogen } \\
\text { (Hemibiotroph) }\end{array}$ \\
\hline Mycosphaerella graminicola & Fungi & Ascomycota & Pezizomycotina & $\begin{array}{l}\text { Plant pathogen } \\
\text { (Hemibiotroph) }\end{array}$ \\
\hline Neurospora crassa & Fungi & Ascomycota & Pezizomycotina & Saprotroph \\
\hline Podospora anserine & Fungi & Ascomycota & Pezizomycotina & Saprotroph \\
\hline Candida albicans & Fungi & Ascomycota & Saccharomycotina & Animal pathogen \\
\hline Saccharomyces cerevisiae S288C & Fungi & Ascomycota & Saccharomycotina & Saprotroph \\
\hline Schizosaccharomyces pombe & Fungi & Ascomycota & Taphrinomycotina & Saprotroph \\
\hline Heterobasidion irregular TC 32-1 & Fungi & Basidiomycota & Agaricomycotina & $\begin{array}{l}\text { Plant pathogen } \\
\text { (Necrotroph) }\end{array}$ \\
\hline Laccaria bicolor & Fungi & Basidiomycota & Agaricomycotina & Saprotroph \\
\hline Phanerochaete chrysosporium & Fungi & Basidiomycota & Agaricomycotina & Saprotroph \\
\hline Serpula lacrymans & Fungi & Basidiomycota & Agaricomycotina & Saprotroph \\
\hline Cryptococcus neoformans var. grubii H99 & Fungi & Basidiomycota & Agricomycotina & Animal pathogen \\
\hline Melampsora laricis-populina & Fungi & Basidiomycota & Pucciniomycotina & $\begin{array}{l}\text { Plant pathogen } \\
\text { (Biotroph) }\end{array}$ \\
\hline Puccinia graminis & Fungi & Basidiomycota & Pucciniomycotina & $\begin{array}{l}\text { Plant pathogen } \\
\text { (Biotroph) }\end{array}$ \\
\hline Ustilago maydis 521 & Fungi & Basidiomycota & Ustilaginomycotina & $\begin{array}{l}\text { Plant pathogen } \\
\text { (Hemibiotroph) }\end{array}$ \\
\hline Allomyces macrogynus & Fungi & Blastocladiomycota & $\mathrm{N} / \mathrm{D}$ & Saprotroph \\
\hline Batrachochytrium dendrobatidis JAM81 & Fungi & Chytridiomycota & N/D & Animal pathogen \\
\hline Phycomyces blakesleeanus & Fungi & Zygomycota & Mucoromycotina & Saprotroph \\
\hline Rhizopus oryzae & Fungi & Zygomycota & Mucoromycotina & Saprotroph \\
\hline Phytophthora infestans & Chromista & Oomycota & Oomycotina & Plant pathogen \\
\hline Arabidopsis thaliana & Viridiplantae & Streptophyta & N/D & \\
\hline Oryza sativa & Viridiplantae & Streptophyta & N/D & \\
\hline Dorosophila melanogaster & Metazoa & Arthropoda & N/D & \\
\hline Caenorhabditis elegans & Metazoa & Nematoda & N/D & \\
\hline Homo sapiens & Metazoa & Chordata & Craniata & \\
\hline
\end{tabular}

* Information about life style and host ranges are shown only for 29 fungal and Oomycete species.

Cross-link with the CFGP 2.0 for further analysis

The FPDB web site supports "Favorite", a personal storage and analysis hub powered by the CFGP 2.0 [25]. In the My Data menu, users can create and manage their own data collections, which are synchronized with the CFGP 2.0. The FPDB website is also featured with i) gene family distribution, ii) BLAST search, iii) BLASTMatrix search and iv) functional domain browser. Users can also use their Favorites in the CFGP 2.0, providing more analysis options.

\section{Conclusions}

The FPDB is developed to take the advantages of a number of fully sequenced fungal genomes and to provide fungicentric platform for studying PCWDEs. The FPDB could 


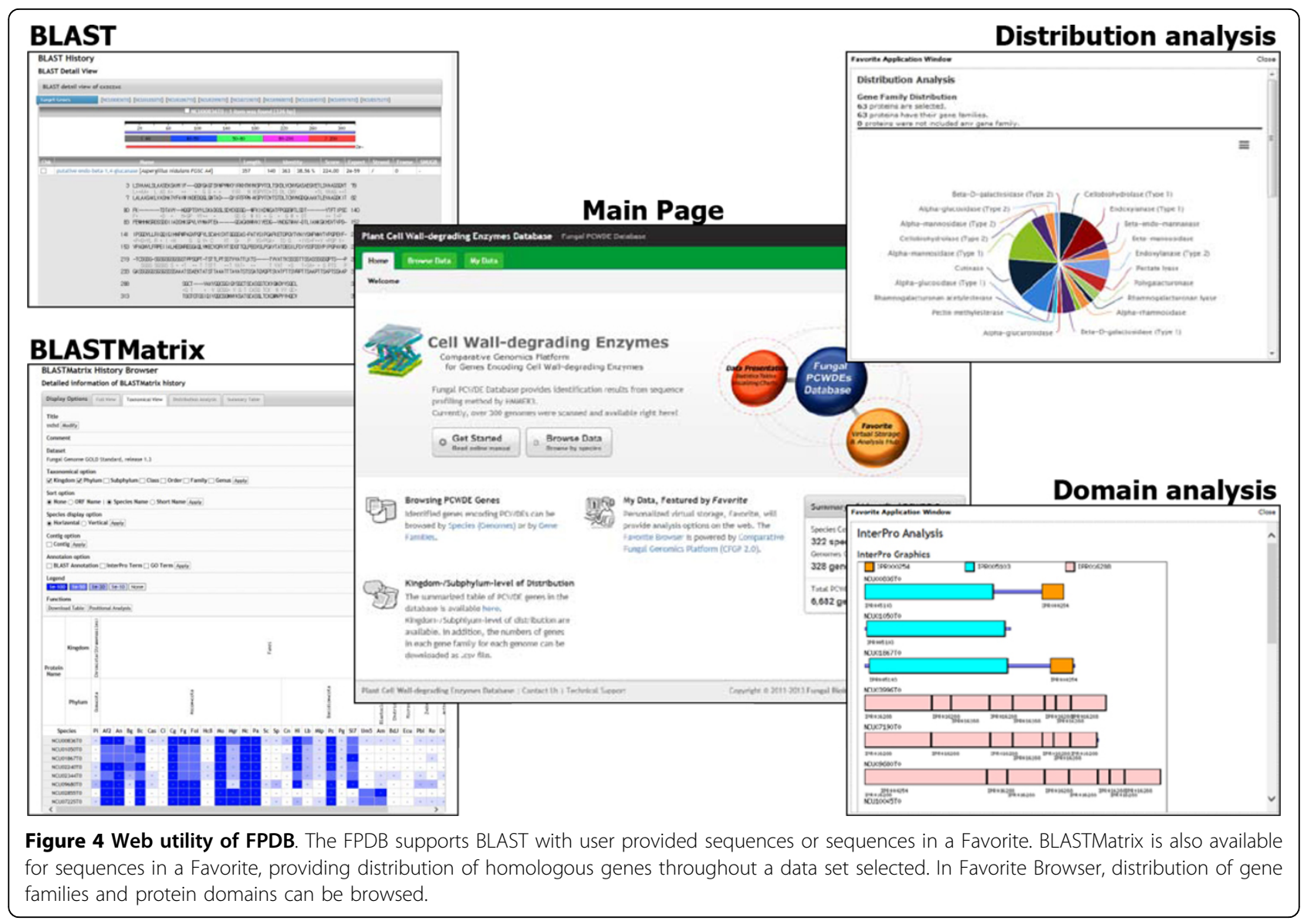

be used for i) selection of target genes that affect fungal pathogenicity, ii) making in silico combinations of PCWDEs for degrading certain substrate and iii) starting material for fungal evolutionary studies of gene families belong to PCWDEs. The web resource we developed provides i) kingdom-/subphylum-wide overview of PCWDEs in fungi with browsing pages and distribution charts, ii) domain visualization function, iii) homology search functions (BLAST and BLASTMatrix) and iv) a bridge to connect with the CFGP 2.0 for flexible data exchange and further analysis. To provide more comprehensive research environment, the FPDB will be updated with more PCWDE gene families, useful analysis tools and up-to-date genome sequences. Taken together, the FPDB can serve as a fungi-centric comparative genomics resource for studying PCWDEs.

\section{Methods}

\section{Collection of protein sequences for construction of sequence profiles}

155,095 protein sequences covering 33 gene families were downloaded from NCBI Protein Database with keywords of gene family names. To investigate fungi-centered gene distribution and ensure representativeness of sequence profiles, sequences that are partial or from other kingdoms were discarded, hence 1,344 fungal protein sequences were chosen for building 22 sequence profiles, including five subfamilies (Table 1). In particular, the sequence profile for beta-D-galactosidase (Type 2) was constructed by the protein sequences collected from the UniProtKB/ SwissProt [11].

\section{Collection of proteome sequences}

Protein sequences of 328 genomes (Additional file 1) were obtained from the standardized genome warehouse of the CFGP 2.0 [25].

\section{A constructed pipeline for genes encoding PCWDEs}

To identify genes encoding PCWDEs, HMMER3 package [26] was exploited to build sequence profiles and predict putative genes. InterPro scan [27] was also used in determination of consensus domains for each gene family. If there is more than one domain profile for one gene family, they were divided into subfamilies with a designation like "Type 1" and "Type 2". Concatenated domain sequences for each gene family were subjected to multiple sequence alignment by using MUSCLE built in MEGA5 [28]. Subsequently, the alignments were manually trimmed, then 
used as input when building sequence profiles by using hmmbuild. hmmsearch in the HMMER3 package [26] was used for identifying candidate genes encoding PCWDEs from the 328 proteomes from 322 species (Figure 1 and Table 1).

\section{Elimination of redundancy}

Because certain gene families could share high sequence homology, one gene could be predicted in multiple gene families. To eliminate this redundancy, the gene family which marked the highest score was assigned and the rest of predictions for that sequence were discarded.

\section{Evaluation of the pipeline}

In order to evaluate the confidence level of the pipeline, we prepared positive and negative sets from UniProtKB/ SwissProt [11]. The positive set was defined as the protein sequences annotated as the PCWDEs investigated in this study. Subsequently, the protein sequences used in construction of the 22 sequence profiles were filtered out from the positive set. The protein sequences of enzymes that are closely related to PCWDEs were determined as the negative set. Only the fungal sequences having UniProt accession were retrieved among the sequences of glycosyltransferase (GT), polysaccharide lyase (PL) and carbohydrate esterase (CE) from the CAZY database [8]. GT, PL and $C E$ are carbohydrate active enzymes like PCWDEs, but they have different catalytic activities. Therefore it makes these sequences a good negative data set to evaluate the discrimination power of the PCWDE identification pipeline. In total of 128 and 344 sequences were selected for the positive and negative sets, respectively.

\section{Reconciliation analysis}

A phylogeny of genomes was constructed by CVtree2 [29]. Whole proteome sequences were used as input of the CVtree2 with K-tuple length of seven. Distance matrix was converted into neighbor-joining tree by neighbor in PHYLIP package v3.69 [30]. Multiple sequence alignment and construction of phylogenetic tree were performed by using T-Coffee [31] and MEGA5 [28], respectively. To investigate gene duplications and losses during the evolution, reconciliation analysis was performed by using Notung 2.6 [32]. For phylogenomic analyses, genomes and proteomes were prepared from 34 species covering 28 fungi, one Oomycete, two plants and three animals. The 28 fungi cover 6 phyla with diverse life styles and infection styles (Table 2).

\section{Availability of supporting data}

All data described in this paper can be freely accessed through the FPDB web site at http://pcwde.riceblast.snu. ac.kr/ via the latest versions of Google Chrome, Mozilla Firefox, Microsoft Internet Explorer (9 or higher) and
Apple Safari. The data sets supporting the results of this article are included within the article and its additional files.

\section{Additional material}

Additional file 1: Summary of the number of predicted genes encoding PCWDEs in $\mathbf{3 2 8}$ genomes. List of taxonomically ordered 328 genomes archived in the FPDB. The number of predicted genes for each gene family is listed.

Additional file 2: Expression of PCWDEs in M. oryzae reported in the previous studies. The 33 genes encoding PCWDEs in M. oryzae that are expressed in planta apoplastic secretome analysis and/or transcriptomic profiling are listed.

Additional file 3: Distribution of genes encoding PCWDEs in 215 fungal or Oomycete genomes. The numbers of genes for each gene family are listed along with the list of 215 fungi and Oomycetes which is ordered by life style and taxonomy.

\section{Competing interests}

The authors declare that they have no competing interests.

\section{Authors' contributions}

$\mathrm{JC}$ and YHL designed this project. JC developed the database, web interfaces and identification pipeline. JC and KTK conducted data analysis. JC, KTK, JJ and YHL wrote the manuscript. All the authors read and approved the final manuscript.

\section{Acknowledgements}

This work was supported by the National Research Foundation of Korea grant funded by the Korea government (2008-0061897 and 2013-003196) and the Next-Generation BioGreen 21 Program of Rural Development Administration in Korea (PJ00821201). JC, KTK and JJ are grateful for a graduate fellowship through the Brain Korea 21 Program.

\section{Declarations}

The publication costs for this article were funded by the National Research Foundation of Korea grant (2008-0061897).

This article has been published as part of BMC Genomics Volume 14 Supplement 5, 2013: Twelfth International Conference on Bioinformatics (InCoB2013): Computational biology. The full contents of the supplement are available online at http://www.biomedcentral.com/bmcgenomics/ supplements/14/S5.

\section{Authors' details}

${ }^{1}$ Fungal Bioinformatics Laboratory, Seoul National University, Seoul 151-921, Korea. ${ }^{2}$ Department of Agricultural Biotechnology, Seoul National University, Seoul 151-921, Korea. ${ }^{3}$ Center for Fungal Pathogenesis, Seoul National University, Seoul 151-921, Korea. ${ }^{4}$ Center for Fungal Genetic Resource, Seoul National University, Seoul 151-921, Korea. ${ }^{5}$ Plant Genomics and Breeding Institute, Seoul National University, Seoul 151-921, Korea. ${ }^{6}$ Research Institute for Agriculture and Life Sciences, Seoul National University, Seoul 151-921, Korea.

Published: 16 October 2013

\section{References}

1. Skamnioti P, Gurr SJ: Magnaporthe grisea cutinase2 mediates appressorium differentiation and host penetration and is required for full virulence. Plant Cell 2007, 19(8):2674-2689.

2. Rogers LM, Flaishman MA, Kolattukudy PE: Cutinase gene disruption in Fusarium solani f sp pisi decreases its virulence on pea. Plant Cell 1994, 6(7):935-945.

3. Wu SC, Halley JE, Luttig C, Fernekes LM, Gutierrez-Sanchez G, Darvill AG, Albersheim P: Identification of an endo-beta-1,4-D-xylanase from Magnaporthe grisea by gene knockout analysis, purification, and heterologous expression. Appl Environ Microbiol 2006, 72(2):986-993. 
4. King BC, Waxman KD, Nenni NV, Walker LP, Bergstrom GC, Gibson DM: Arsenal of plant cell wall degrading enzymes reflects host preference among plant pathogenic fungi. Biotechnol Biofuels 2011, 4:4.

5. ten Have A, Mulder W, Visser J, van Kan JA: The endopolygalacturonase gene $B c p g 1$ is required for full virulence of Botrytis cinerea. Mol PlantMicrobe Interact 1998, 11(10):1009-1016.

6. Shieh MT, Brown RL, Whitehead MP, Cary JW, Cotty PJ, Cleveland TE, Dean RA: Molecular genetic evidence for the involvement of a specific polygalacturonase, $\mathrm{P} 2 \mathrm{c}$, in the invasion and spread of Aspergillus flavus in cotton bolls. Appl Environ Microbiol 1997, 63(9):3548-3552.

7. Oeser B, Heidrich PM, Muller U, Tudzynski P, Tenberge KB: Polygalacturonase is a pathogenicity factor in the Claviceps purpurea/rye interaction. Fungal Genet Biol 2002, 36(3):176-186.

8. Cantarel BL, Coutinho PM, Rancurel C, Bernard T, Lombard V, Henrissat B: The Carbohydrate-Active EnZymes database (CAZy): an expert resource for Glycogenomics. Nucleic Acids Res 2009, 37(Database):D233-238.

9. van den Brink J, de Vries RP: Fungal enzyme sets for plant polysaccharide degradation. Appl Microbiol Biotechnol 2011, 91(6):1477-1492.

10. Schiott M, De Fine Licht HH, Lange L, Boomsma JJ: Towards a molecular understanding of symbiont function: identification of a fungal gene for the degradation of xylan in the fungus gardens of leaf-cutting ants. BMC Microbiol 2008, 8:40.

11. The UniProt Consortium: Reorganizing the protein space at the Universal Protein Resource (UniProt). Nucleic Acids Res 2012, 40(D1) D71-D75.

12. Wilson DB: Three microbial strategies for plant cell wall degradation. Ann NY Acad Sci 2008, 1125:289-297.

13. Minic Z: Physiological roles of plant glycoside hydrolases. Planta 2008, 227(4):723-740.

14. Plattner F, Soldati-Favre D: Hijacking of host cellular functions by the Apicomplexa. Annu Rev Microbiol 2008, 62:471-487.

15. Jakob A, Bryjak J, Polakovic M: Selection of a method for determination of activity of pectinolytic enzymes in berry fruit materials. Chem Pap 2009, 63(6):677-682.

16. Choi J, Park J, Kim D, Jung K, Kang S, Lee YH: Fungal secretome database: integrated platform for annotation of fungal secretomes. BMC Genomics 2010, 11:105.

17. Chen S, Songkumarn P, Venu RC, Gowda M, Bellizzi M, Hu J, Liu W, Ebbole D, Meyers B, Mitchell T, et al: Identification and characterization of in planta-expressed secreted effector proteins from Magnaporthe oryzae that induce cell death in rice. Mol Plant-Microbe Interact 2013, 26(2):191-202.

18. Kim SG, Wang Y, Lee KH, Park ZY, Park J, Wu J, Kwon SJ, Lee YH, Agrawal GK, Rakwal R, et al: In-depth insight into in vivo apoplastic secretome of rice-Magnaporthe oryzae interaction. J Proteomics 2013, 78:58-71.

19. Yakoby N, Freeman S, Dinoor A, Keen NT, Prusky D: Expression of pectate lyase from Colletotrichum gloesosporioides in C. magna promotes pathogenicity. Mol Plant-Microbe Interact 2000, 13(8):887-891.

20. Isshiki A, Akimitsu K, Yamamoto M, Yamamoto H: Endopolygalacturonase is essential for citrus black rot caused by Alternaria citri but not brown spot caused by Alternaria alternata. Mol Plant-Microbe Interact 2001, 14(6):749-757

21. Dashtban M, Schraft $H$, Syed TA, Qin W: Fungal biodegradation and enzymatic modification of lignin. Int J Biochem Mol Biol 2010, 1(1):36-50.

22. McCann M, Roberts K: Architecture of the primary cell wall. The cytoskeletal basis of plant growth and form 1991, 109-129.

23. Scott-Craig JS, Panaccione DG, Cervone F, Walton JD: Endopolygalacturonase is not required for pathogenicity of Cochliobolus carbonum on maize. Plant Cell 1990, 2(12):1191-1200.

24. Ma LJ, Ibrahim AS, Skory C, Grabherr MG, Burger G, Butler M, Elias M, Idnurm A, Lang BF, Sone T, et al: Genomic analysis of the basal lineage fungus Rhizopus oryzae reveals a whole-genome duplication. PLoS Genet 2009, 5(7):e1000549.

25. Choi J, Cheong K, Jung K, Jeon J, Lee GW, Kang S, Kim S, Lee YW, Lee YH: CFGP 2.0: a versatile web-based platform for supporting comparative and evolutionary genomics of fungi and Oomycetes. Nucleic Acids Res 2013, 41(Database):D714-719.

26. Finn RD, Clements J, Eddy SR: HMMER web server: interactive sequence similarity searching. Nucleic Acids Res 2011, 39(Web Server):W29-37.
27. Hunter S, Jones P, Mitchell A, Apweiler R, Attwood TK, Bateman A, Bernard T, Binns D, Bork P, Burge $S$, et al: InterPro in 2011: new developments in the family and domain prediction database. Nucleic Acids Res 2012, 40(Database):D306-312.

28. Tamura K, Peterson D, Peterson N, Stecher G, Nei M, Kumar S: MEGA5: molecular evolutionary genetics analysis using maximum likelihood, evolutionary distance, and maximum parsimony methods. Mol Biol Evol 2011, 28(10):2731-2739.

29. Xu Z, Hao B: CVTree update: a newly designed phylogenetic study platform using composition vectors and whole genomes. Nucleic Acids Res 2009, 37(Web Server):W174-178.

30. Felsenstein J: PHYLIP (Phylogeny Inference Package) version 3.6. Distributed by the author Department of Genome Sciences, University of Washington, Seattle 2005.

31. Di Tommaso P, Moretti S, Xenarios I, Orobitg M, Montanyola A, Chang JM, Taly JF, Notredame C: T-Coffee: a web server for the multiple sequence alignment of protein and RNA sequences using structural information and homology extension. Nucleic Acids Res 2011, 39(Web Server):W13-17.

32. Stolzer M, Lai H, Xu M, Sathaye D, Vernot B, Durand D: Inferring duplications, losses, transfers and incomplete lineage sorting with nonbinary species trees. Bioinformatics 2012, 28(18):i409-i415.

doi:10.1186/1471-2164-14-S5-S7

Cite this article as: Choi et al:: Fungal plant cell wall-degrading enzyme database: a platform for comparative and evolutionary genomics in fungi and Oomycetes. BMC Genomics 2013 14(Suppl 5):S7.

\section{Submit your next manuscript to BioMed Central and take full advantage of:}

- Convenient online submission

- Thorough peer review

- No space constraints or color figure charges

- Immediate publication on acceptance

- Inclusion in PubMed, CAS, Scopus and Google Scholar

- Research which is freely available for redistribution

Submit your manuscript at www.biomedcentral.com/submit
C Biomed Central 